\title{
Teor de histamina na musculatura branca e vermelha da sardinha verdadeira (Sardinella brasiliensis)
}

\section{Amount of histamine produced in the white and red musculature of the Sardinella brasiliensis}

\author{
Patrícia C. M. Soares, ${ }^{\star}$ Eliane T. Mársico, ${ }^{* *}$ Robson M. Franco, ${ }^{* *}$ Leila G. Sobreiro**
}

\begin{abstract}
Resumo
Entre as aminas biogênicas produzidas no pescado durante o processo de deterioração, destaca-se a histamina, proveniente da descarboxilação do aminoácido histidina. Sabe-se que nos peixes de carne escura, a musculatura branca é mais rica neste aminoácido do que a musculatura vermelha, em decorrência dos aspectos bioquímicos e fisiológicos necessários à vida do animal. Tendo em vista a importância da produção da histamina, seja para a análise do frescor ou para estimar o potencial de risco para a saúde do consumidor, este estudo teve como objetivo avaliar a produção de histamina na musculatura branca e vermelha de sardinhas (Sardinella brasiliensis), através da cromatografia de camada delgada. As amostras foram divididas em dois lotes, sendo um inoculado com Morganella morganii e outro não inoculado. Metade das amostras foi armazenada sob refrigeração $\left(1^{\circ} \mathrm{C} \pm 1^{\circ} \mathrm{C}\right)$ e o restante sob temperatura de $25^{\circ} \mathrm{C}$. Nas amostras não inoculadas mantidas sob refrigeração, a produção de histamina foi mais precoce e inicialmente mais intensa na musculatura branca do que na vermelha. Nesta mesma temperatura, as amostras inoculadas apresentaram teores acima de $10 \mathrm{mg} / 100 \mathrm{~g}$ já no sétimo dia de análise, para os dois tipos de musculatura. Nas amostras mantidas sob temperatura ambiente, inoculadas ou não, a produção de histamina alcançou o limite máximo permitido após 12 horas de estocagem, nas duas musculaturas. Apesar da produção de histamina ter sido, em condições adequadas de refrigeração $\left(1^{\circ} \mathrm{C}\right)$, inicialmente maior na musculatura branca, esta diferença não afeta o grau de aceitabilidade do produto para este parâmetro, uma vez que o nível máximo permitido foi atingido igualmente no $11^{\circ}$ dia de estocagem.
\end{abstract}

Palavras-chave: pescado; histamina; músculo branco; músculo vermelho.

\begin{abstract}
Among the biogenic amines formed in fish during the deterioration process stands out histamine, originating from the decarboxylation of histidine amino acid. It is known that, in fishes with darker flesh, the white musculature is richer in this amino acid than the red musculature, due to the biochemical and physiologic characteristics necessary to the animal's life. In view of the importance of histamine production, whether for freshness analysis or as potential risk for the consumer's health, this work had as objective to evaluate the amount of histamine produced in the white and red musculature of the Sardinella brasiliensis, during the storage period up to deterioration, through thin layer chromatography. In the non-inoculated samples kept refrigerated the histamine production formed in the white musculature of the Sardinella brasiliensis occurred earlier and in larger levels that in the red. In the same temperature, the inoculated samples presented contents above $10 \mathrm{mg} / 100 \mathrm{~g}$ already at day seventh of analysis for the two types. In the eleventh day of evaluation, both the white musculature and the red musculature reached values over $10 \mathrm{mg} / 100 \mathrm{~g}$. In those samples inoculated or not and kept at room temperature, the histamine production reached the maximum limit allowed after 12 hours of storage (white and red musculatures). In spite of the histamine production having been, for most of the time, larger in the white musculature, kept refrigerated $\left(1^{\circ} \mathrm{C}\right)$ this difference doesn't have an effect on the product level of acceptability for this parameter, since the maximum level allowed was likewise reached in the eleventh day.
\end{abstract}

Keywords: fish; histamine; white muscle; red muscle.

\section{Introdução}

Um dos maiores riscos no que diz respeito ao consumo de pescado é a produção de aminas, que ocorre devido à ação de enzimas de origem bacteriana, as quais têm a capacidade de descarboxilar certos aminoácidos. Os tipos e teores de aminas formadas são afetados pela composição de aminoácidos, pela microbiota natural e contaminante do pei- xe e pelas condições de captura, manuseio e armazenamento (Brandão, 1996).

O acúmulo de aminas nos alimentos dependerá da disponibilidade de aminoácidos livres, da presença de microrganismos com atividade descarboxilante sobre aminoácidos, da existência de condições favoráveis para o crescimento de microrganismos e para a produção e ação de enzimas descarboxilantes. Os alimentos que apresentam uma maior

\footnotetext{
* Mestranda do Departamento de Tecnologia de Alimentos - Fac. Veterinária - UFF - Brasil. e-mail:patmoch@hotmail.com

** Professores do Departamento de Tecnologia de Alimentos - Fac. Veterinária - UFF - Brasil
} 
possibilidade de conter aminas biogênicas são aqueles que apresentam uma elevada carga protéica. Microrganismos com atividade descarboxilante sobre aminoácidos podem fazer parte da microbiota associada ao alimento, ser introduzidos para obter produtos fermentados, ou ainda por contaminação antes, durante ou depois do processamento (Halász et al.,1994). Alimentos fermentados tais como vinho, salame e molho de soja podem conter histamina, além de outras aminas. Depois do peixe, o queijo é o alimento mais implicado em intoxicações histamínicas (Stratton et al., 1991).

Estudos realizados em diferentes países comprovam que peixes da família Scombridae, particularmente atum, bonito, cavala e cavalinha, são os que apresentam níveis mais altos de histidina livre, sendo, conseqüentemente, os mais freqüentes veículos de intoxicação histamínica. No entanto, peixes pertencentes à família Clupeidae, bem como os crustáceos, também podem apresentar níveis relativamente elevados de histidina livre (Huss, 1993).

À parte da histidina livre, aminoácidos também podem ser liberados por atividade proteolítica endógena ou exógena, durante o armazenamento do pescado. Assim, a manutenção de condições de refrigeração e higiênico-sanitárias adequadas, por ocasião da captura, transporte e comercialização, é essencial para se prevenir a formação de aminas. Falhas eventuais nesta cadeia podem propiciar o crescimento de microrganismos e a elevação nos teores de aminas (Lima e Glória, 1999).

As aminas biogênicas são importantes sob ponto de vista de intoxicação alimentar e também como indicadores químicos de deterioração (Shakila et al., 2001). As implicações toxicológicas podem ser variadas: na presença de nitritos, elas podem produzir compostos que podem ser precursores endógenos de $\mathrm{N}$-nitrosaminas; a ingestão de aminas biogênicas pode provocar crise hipertensiva em paciente em tratamento com inibidores da monoaminoxidase; o consumo de alimentos com alto teor de tiramina e outras aminas pode causar cefaléia. Todavia, essas aminas não são consideradas um grave risco para humanos se elas estiverem presentes em baixos níveis ou se o metabolismo não estiver bloqueado geneticamente (Veciana-Nogues et al., 1995). Lima e Glória (1999) ainda relatam a ocorrência de crises de enxaqueca em indivíduos com deficiência genética ou em tratamento com medicamentos inibidores da monoaminoxidase e que as poliaminas, como estão associadas ao crescimento celular, devem ter sua ingestão limitada por pacientes portadores de câncer.

Indivíduos saudáveis podem oxidar (detoxificar) as poliaminas e aminas biogênicas ingeridas através de reações de acetilação e oxidação mediada pelas enzimas monoaminoxidase (MAO), diaminoxidase (DAO) poliaminoxidase (PAO) (Bjeldanes et al., 1978). Pessoas com distúrbios gastrintestinais (gastrite, úlceras estomacal e duodenal, doença de Crohn etc.) estão em risco, porque a atividade da oxidase em seus intestinos está diminuída em relação aos indivíduos saudáveis. Nas mulheres na fase pré-menstrual há um acréscimo na atividade do tipo $\mathrm{B}$ da MAO, o que também pode ser um problema (Bardócz, 1995). Jung e Bjeldanes (1979) verificaram que a espermina e cadaverina aumentaram o transporte de histamina através da parede gastrintestinal.
As aminas encontradas na dieta podem ser classificadas como mono, di e poliaminas, com base na estrutura química. As poliaminas são compostos muito estáveis, capazes de resistir ao calor e sobreviver a condições ácidas e alcalinas (Bardócz, 1995).

Vários trabalhos (Ito, 1957; Lukton e Olcott, 1958; Sakaguchi et al., 1982; Wendakoon et al., 1990; Antoine et al., 2001) têm demonstrado as variações existentes entre os diferentes tipos de musculatura. Sabe-se que, nos peixes de carne escura, a musculatura branca é mais rica neste aminoácido do que a musculatura vermelha, em decorrência dos aspectos bioquímicos e fisiológicos necessários à vida do animal. Até o momento, não existem dados sobre o reflexo desta diferença na produção de histamina durante a deterioração da sardinha, nem, tampouco, é conhecido se ocorre variação significativa quando são adotados e interpretados os padrões legais para esta amina.

A formação de histamina, assim como a diferença na composição de aminoácidos entre o músculo branco e o músculo escuro vem sendo estudada há bastante tempo. Ito (1957) avaliou alguns tipos de pescado de carne branca (Mylio macrocephalus e Fugu poecilonotus) e escura (Scomber japonicus e Trachurus japonicus). Os peixes de carne escura apresentaram um teor alto de histidina, quando comparados aos de carne branca. Entretanto, nos peixes de carne escura, a quantidade de histidina na musculatura branca foi muito superior à vermelha.

Com a finalidade de se avaliar a intensidade de contaminação por bactérias histamina-positivas, Leitão et al. (1983) coletaram amostras de sardinha (Sardinella brasiliensis), cavalinha (Scomber japonicus) e atum albacora (Thunnus alalunga, Bonnaterre) e constataram que a distribuição de bactérias produtoras de histamina parece estar bastante disseminada, tanto na superfície como nas vísceras das diversas espécies. Pôde-se observar, também, que Proteus morganii foi a bactéria histamina positiva mais freqüentemente isolada $(58,8 \%)$, seguida $P$. rettgeri e outras espécies de Proteus (12,4\%), Vibrio (11,4\%), Aeromonas (9,3\%) e espécies de Acinetobacter, Pseudomonas, Enterobacter e Klebsiella. Ainda no mesmo estudo, o processo de formação de histamina em sardinhas inoculadas com Proteus morganii foi mais intenso à temperatura na faixa de $15^{\circ}$ a $35^{\circ} \mathrm{C}$, sendo praticamente nulo às temperaturas de refrigeração, abaixo de $7^{\circ} \mathrm{C}$. Concluíram que, em condições adequadas de substrato e temperatura, a formação de histamina foi relativamente rápida, sendo que concentrações potencialmente tóxicas foram atingidas em menos de 24 horas.

No Brasil, o limite legal para histamina é de 100 ppm no músculo para as espécies pertencentes às famílias Scombridae, Scombresocidae, Clupeidae, Coryphaenidae e Pomatomidae (Brasil, 1997).

Tendo em vista os fatores relatados, este estudo teve como objetivo avaliar a produção de histamina na musculatura branca e vermelha de sardinhas (Sardinella brasiliensis), armazenadas sob refrigeração $\left(1^{\circ} \mathrm{C} \pm 1^{\circ} \mathrm{C}\right)$ e sob temperatura de $25^{\circ} \mathrm{C}$, não inoculadas e inoculadas com Morganella morganii, além de observar se os valores de histamina obtidos para os diferentes tipos de musculatura originam interpretações variadas nos padrões legais para este produto. 


\section{Material e métodos}

Foram utilizadas 78 amostras de sardinhas (Sardinella brasiliensis) frescas, obtidas imediatamente após a captura, acondicionadas em embalagens plásticas e transportadas em recipiente isotérmico com gelo aos Laboratórios de Controle Físico-Químico e Controle Microbiológico da Faculdade de Veterinária da Universidade Federal Fluminense (UFF).

Porções da musculatura branca e vermelha foram separadas e, em seguida, inseridas em placas de petri esterilizadas. Metade de cada uma destas amostras foi inoculada com $1 \mathrm{~mL}$ do cultivo de Morganella morgani, sendo a outra metade reservada para controle. O cultivo foi distribuído assepticamente na superfície das amostras, usando uma pipeta esterilizada de $1 \mathrm{~mL}$. Das amostras inoculadas, metade ficou em temperatura ambiente $\left(25^{\circ} \mathrm{C}\right)$ e a outra parte em temperatura de refrigeração $\left(1^{\circ} \mathrm{C}\right)$. A metade das amostras que não foi inoculada foi mantida sob as mesmas condições, servindo de controle.

Cada amostra correspondeu a um pool obtido a partir de quatro sardinhas. As amostras mantidas sob refrigeração $\left(1^{\circ} \mathrm{C}\right)$ foram analisadas em dias alternados até a deterioração do pescado. As amostras a $25^{\circ} \mathrm{C}$ foram analisadas de $12 \mathrm{em} 12$ horas até completarem 36 horas.

\section{Procedimento de inoculação da Morganella morganii (Gingerich, 1999)}

Uma alíquota de $1 \mathrm{~mL}$ da cultura de Morganella morganii in vitro foi adicionada em $9 \mathrm{~mL}$ de caldo tripticase soja. Incubou-se por 24 horas a $37^{\circ} \mathrm{C}$. Decorrido o tempo mencionado, $1 \mathrm{~mL}$ da cultura de 24 horas foi introduzido em um segundo tubo com $9 \mathrm{ml}$ de caldo tripticase soja, que foi incubado por quatro horas a $37^{\circ} \mathrm{C}$. O número de células bacterianas por mililitro foi comparado através da tabela de Mac Farland (tubo 1 - aproximadamente de $10^{6}$ a $10^{8} \mathrm{UFC} / \mathrm{mL}$ ). Semeou-se por Pour Plate, no meio ágar tripticase soja, nas diluições de $10^{-1}$ a $10^{-10}$, com o objetivo de se confirmar a contagem de UFC presente no inóculo.

\section{Análises físico-químicas}

Produção de histamina por cromatografia de camada delgada (Schutz, Chang e Bjeldanes, 1976).

Foi pesado $1 \mathrm{~g}$ de cada amostra a ser estudada em um tubo para centrífuga onde se adicionaram $2 \mathrm{~mL}$ de metanol. Homogeneizou-se e aqueceu-se em banho-maria sob agitação até a fervura. Centrifugouse por três minutos a 3.000 RPM.

As placas de alumínio com sílica gel (Sílica gel 60 $\mathrm{F}_{254}$ Merk) foram preparadas e, a $1,5 \mathrm{~cm}$ da borda inferior, marcaram-se seis pontos, onde foram aplicadas as amostras $(10 \mu \mathrm{L})$ e os padrões (em volumes de 1, 2,5, 5,0, 7,5 e $10 \mu \mathrm{L}$ ) com o auxílio de uma microsseringa de 10 microlitros. A solução padrão foi preparada com Histamina-2 $\mathrm{HCl}$ (Merck) em metanol. Cada microlitro da solução padrão correspondeu a $1 \mathrm{mg} / 100 \mathrm{~g}$ de histamina.

O preparo do solvente incluiu uma mistura de acetona e hidróxido de amônia (20:1) em tanque de cromatografia. A placa já preparada foi colocada no interior do tanque para "corrida da cromatografia". Após este procedimento secou-se a placa e aspergiu-se com solução a $0,3 \%$ de ninhidrina para revelação da placa. Secou-se até a obtenção de uma boa visualização dos padrões e das amostras, e interpretou-se de acordo com a migração e a intensidade das manchas sobre a camada de sílica.

\section{Bases Voláteis Totais (BVT) (Brasil, 1981).}

Para elaboração deste método, seguiu-se o procedimento descrito no Manual do LANARA (Brasil, 1981).

\section{Análise estatística}

Os resultados foram submetidos ao teste T de Student com o objetivo de comparar os dados obtidos. O software utilizado foi o BioEstat 2.0 (Ayres, 2000).

\section{Resultados e discussão}

\section{Histamina}

O início da produção de histamina na musculatura branca foi mais precoce que na vermelha tanto nas amostras não inoculadas como nas inoculadas mantidas sob refrigeração. Nas amostras estocadas sob refrigeração e inoculadas, a produção de histamina na musculatura branca atingiu um teor $>10 \mathrm{mg} / 100 \mathrm{~g}$ no $3^{\circ}$ dia de estocagem. Portanto, maior que o limite aceitável de 100ppm (10mg/100g) (Brasil, 1997). Na musculatura vermelha, a produção de histamina, neste mesmo dia, ainda era menor que $2 \mathrm{mg} / 100 \mathrm{~g}$. No 5 o dia de estocagem este perfil foi mantido para a musculatura branca, enquanto na vermelha houve um incremento, demonstrando um teor entre 7,5 e $10 \mathrm{mg} / 100 \mathrm{~g}$. No $7^{\circ}$ dia a musculatura vermelha atingiu o limite preconizado pela legislação em vigor.

Nas amostras não inoculadas, no 50 dia de estocagem a musculatura branca evidenciou valores inferiores a $2 \mathrm{mg} / 100 \mathrm{~g}$ e na musculatura vermelha ainda não havia formação deste composto. No $7^{\circ}$ dia, houve um ligeiro aumento em ambas as amostras. No 9o dia a porção muscular branca apresentou entre 2 e $5 \mathrm{mg} / 100 \mathrm{~g}$ de histamina, enquanto a vermelha já apresentava teores superiores a $5 \mathrm{mg} / 100 \mathrm{~g}$. Valores maiores que $10 \mathrm{mg} / 100 \mathrm{~g}$ foram constatados no 11 o dia de estocagem para as duas porções musculares analisadas.

Tabela 1 - Resultados referentes à formação de histamina por CCD em amostras não inoculadas e inoculadas com Morganella morganii de musculatura branca e vermelha de sardinhas (Sardinella brasiliensis) mantidas sob temperatura de $1^{\circ} \mathrm{C}$.

\begin{tabular}{ccccc}
\hline & $\begin{array}{c}\text { Amostras não } \\
\text { inoculadas }\end{array}$ & \multicolumn{3}{c}{ Amostras inoculadas } \\
\hline $\begin{array}{c}\text { Dias de estocagem } \\
\left(1^{\circ} \mathbf{C} \pm 1^{\circ} \mathbf{C}\right)\end{array}$ & Branca & Vermelha & Branca & Vermelha \\
\hline $\mathbf{1}$ & $\mathrm{ND}$ & $\mathrm{ND}$ & $\mathrm{ND}$ & $\mathrm{ND}$ \\
$\mathbf{3}$ & $\mathrm{ND}$ & $\mathrm{ND}$ & $>10$ & $<2$ \\
$\mathbf{5}$ & $<2$ & $\mathrm{ND}$ & $>10$ & $7,5>10$ \\
$\mathbf{7}$ & $\cong 2$ & $<2$ & $>10$ & $>10$ \\
$\mathbf{9}$ & $2>5$ & $>5$ & - & - \\
$\mathbf{1 1}$ & $>10$ & $>10$ & - & - \\
\hline
\end{tabular}

Obs: Resultados expressos em mg/100 g. ND: não detectável. 
Este aumento gradual nos níveis de histamina, assim como valores mais altos para a musculatura branca, não foi observado nas amostras mantidas a $25^{\circ} \mathrm{C}$, uma vez que todas as amostras, inoculadas ou não, alcançaram o limite máximo após 12 horas do início das análises.

Tabela 2 - Resultados referentes à formação de histamina por CCD em amostras não inoculadas e inoculadas com Morganella morganii de musculatura branca e vermelha de sardinhas (Sardinella brasiliensis) mantidas sob temperatura de $25^{\circ} \mathrm{C}$.

\begin{tabular}{ccccc}
\hline & $\begin{array}{c}\text { Amostras } \\
\text { não inoculadas }\end{array}$ & \multicolumn{3}{c}{ Amostras inoculadas } \\
\hline Tempo (horas) & Branca & Vermelha & Branca & Vermelha \\
\hline $\mathbf{0}$ & ND & ND & ND & ND \\
$\mathbf{1 2}$ & $>10$ & $>10$ & $>10$ & $>10$ \\
$\mathbf{2 4}$ & $>10$ & $>10$ & $>10$ & $>10$ \\
$\mathbf{3 6}$ & $>10$ & $>10$ & $>10$ & $>10$ \\
\hline
\end{tabular}

Obs: Resultados expressos em mg/100g. ND: não detectável.

Os resultados obtidos são similares aos descritos por Ito (1957), que observou nos peixes de carne escura uma quantidade de histidina na musculatura branca muito superior à vermelha, resultados também confirmados por Lukton e Olcott (1958), Sakaguchi et al. (1982) e Antoine et al. (2001), que encontraram altos teores de histidina livre na musculatura branca dos pescados avaliados, mostrando que há uma grande propensão à produção de altos níveis de histamina nesta musculatura.

Entretanto, resultados contrários são relatados por Wendakoon et al. (1990), que observaram níveis de produção de histamina mais pronunciados na musculatura escura que na branca da cavalinha. Cabe ressaltar que estes autores encontraram maiores teores de histidina na musculatura branca que na vermelha.

Quando comparamos os resultados obtidos em relação à temperatura de estocagem, observamos que a temperatura de $1^{\circ} \mathrm{C}$ foi um fator importante para limitar e controlar a produção de histamina nas musculaturas estudadas. Eitenmiller et al. (1981) demonstraram que uma rápida atividade da histidina descarboxilase com produção de histamina ocorreu em filés de atum inoculados com $P$. morganii e estocados a $24^{\circ} \mathrm{C}$ e $30^{\circ} \mathrm{C}$. O máximo da atividade da histidina descarboxilase ocorreu após 12 horas nas duas temperaturas. Resultados semelhantes foram encontrados neste estudo, com valores de histamina acima de $10 \mathrm{mg} / 100 \mathrm{~g}$ após $12 \mathrm{~h}$ de estocagem a $25^{\circ} \mathrm{C}$, em sardinhas inoculadas ou não.

Leitão (1983) verificou que a produção de histamina em amostras de sardinha, cavalinha e atum foi mais intensa entre $15^{\circ} \mathrm{C}$ e $35^{\circ} \mathrm{C}$, sendo praticamente nula à temperatura de refrigeração abaixo de $7^{\circ} \mathrm{C}$. Este último dado não está de acordo com os obtidos no presente estudo, cuja produção de histamina foi maior que $10 \mathrm{mg} / 100 \mathrm{~g}$ já no 3 o dia de estocagem a $1^{\circ} \mathrm{C}$ para a musculatura branca e entre 7,5 e 10mgno 5 dia para a vermelha.
Silva et al. (1998) encontraram no período de seis dias a $4^{\circ} \mathrm{C}$, uma produção de histamina de $5 \mathrm{mg} / 100 \mathrm{~g}$ e de $50 \mathrm{mg}$ após 24 horas a $22^{\circ} \mathrm{C}$, em amostras inoculadas. De forma semeIhante, nosso estudo revelou uma produção de histamina em torno de $5 \mathrm{mg} / 100 \mathrm{~g}$ no $9^{\circ}$ dia de estocagem a $1^{\circ} \mathrm{C}$, temperatura inferior à atingida pelos referidos autores. À temperatura de $25^{\circ} \mathrm{C}$, também foram demonstrados valores acima de 10mg após 24 horas de estocagem.

A temperatura de refrigeração de $1^{\circ} \mathrm{C}$ utilizada no experimento explica o início tardio da produção de histamina (5 dia na branca e 7ํ na vermelha) nas amostras não inoculadas com M. morganii, quando comparado com a temperatura de $25^{\circ} \mathrm{C}$.

Gingerich et al. (1999), no intuito de mostrar a produção de histamina pela bactéria $M$. morganii, realizaram a inoculação da mesma em Pomatomus saltatrix, comprovando que os maiores níveis de histamina foram alcançados em temperaturas de $10^{\circ} \mathrm{C}$ e $15^{\circ} \mathrm{C}$.

\section{Bases voláteis totais (BVT)}

A determinação de BVT foi realizada com o objetivo de evidenciar a deterioração das amostras.

Para as amostras mantidas sob refrigeração, os teores de BVT aumentaram gradualmente até o $11^{\circ}$ dia, tanto para as amostras não inoculadas como para as inoculadas. O limite máximo permitido, que é de 30mg de N/100g (Brasil, 1997), foi ultrapassado no 5 ㅇ dia, tanto na musculatura vermelha quanto na branca, nas amostras não inoculadas. No que se refere às amostras inoculadas, este limite foi alcançado no quinto dia para a musculatura branca. Para a musculatura vermelha, apesar de bem próximo ao limite máximo no quinto dia, este só foi ultrapassado no 7ㅇ․

Tabela 3 - Valores de BVT (mgN/100g) em amostras da musculatura branca e vermelha de sardinhas (Sardinella brasiliensis) não inoculadas e inoculadas com Morganella morganii mantidas sob temperatura de $1^{\circ} \mathrm{C} \pm 1^{\circ} \mathrm{C}$.

\begin{tabular}{ccccc}
\hline & \multicolumn{2}{c}{ Amostras não inoculadas } & \multicolumn{2}{c}{ Amostras Inoculadas } \\
\hline Dias & Branca & Vermelha & Branca & Vermelha \\
\hline $\mathbf{1}$ & 15,65 & 22,50 & 22,05 & 23,94 \\
$\mathbf{3}$ & 20,66 & 24,82 & 22,68 & 23,31 \\
$\mathbf{5}$ & 31,00 & 36,80 & 31,50 & 29,00 \\
$\mathbf{7}$ & 44,22 & 43,47 & 93,35 & 41,90 \\
$\mathbf{9}$ & 59,59 & 62,49 & & \\
$\mathbf{1 1}$ & 100,80 & 81,90 & - & - \\
\hline
\end{tabular}

Obs: Resultados expressos em mgN/100g.

Nas amostras não inoculadas mantidas sob $25^{\circ} \mathrm{C}$, o limite máximo foi alcançado 24 horas após o início das análises. Nas inoculadas, para a musculatura branca isto aconteceu já nas primeiras 12 horas após, enquanto na vermelha, após 24 horas. 
Tabela 4 - Valores médios de BVT (mgN/100 g) em amostras de musculatura branca e vermelha de sardinhas (Sardinella brasiliensis) não inoculadas e inoculadas com Morganella morganii mantidas sob temperatura de $25^{\circ} \mathrm{C}$.

\begin{tabular}{ccccc}
\hline & \multicolumn{2}{c}{ Amostras não inoculadas } & \multicolumn{2}{c}{ Amostras inoculadas } \\
\hline $\begin{array}{c}\text { Tempo } \\
\text { (horas) }\end{array}$ & Branca & Vermelha & Branca & Vermelha \\
\hline $\mathbf{0}$ & 19,53 & 15,12 & 22,05 & 23,94 \\
$\mathbf{1 2}$ & 19,53 & 21,42 & 32,76 & 25,20 \\
$\mathbf{2 4}$ & 35,28 & 39,06 & 40,32 & 36,54 \\
$\mathbf{3 6}$ & 81,90 & 93,24 & 94,50 & 65,52 \\
\hline
\end{tabular}

Obs: Resultados expressos em mgN/100g.

Observou-se que houve diferença estatisticamente significativa $(p<0,05)$ entre a produção de bases voláteis totais nas porções musculares estudadas nas amostras inoculadas mantidas sob refrigeração $\left(1^{\circ} \mathrm{C}\right)$. Quanto às outras análises, não foram observadas alterações significativas. Porém é conveniente salientar que, apesar de estatisticamente irrelevante, grande parte dos resultados assumiu valores superiores a 30mg/100g que é o limite máximo permitido (Brasil, 1997).

Os valores mais altos de BVT encontrados para a musculatura branca do pescado podem ser explicados em função do estresse sofrido pelo animal durante a captura, gerando maior degradação protéica neste tipo de fibra. Varrik et al. (1992) verificaram um maior catabolismo protéico em fibras brancas do tecido muscular de ratos após o exercício, o que não foi observado nas fibras vermelhas.

Abdalla et al. (1989) relatam índices de BVT com um aumento gradual ao longo do período de armazenamento. Em relação ao limite máximo permitido, as amostras mantidas sob refrigeração $\left(2^{\circ} \mathrm{C}\right)$ também tiveram este limite ultrapassado no $5^{\circ}$ dia. Quanto à histamina, valores 142,28 ppm foram obtidos

\section{Referências}

ABDALLA, M. A.; HASSAN, I. M.; SHALABY, A. R.; NAGUIB, K. Physicochemical and bacteriological changes occurring during storage of sardine fish. Grasa y Aceites, v. 40, n. 6, p. 389-398, 1989.

ANTOINE, F. R.; WEI, C. I.; LITTELL, C. R.; QUINN, B. P.; HOGLE, A. D.; MARSHALL, M. R. Free amino acids in dark and white muscle fish as determined by o-phthaldialdehyde precolumn derivatization. Journal of Food Science, v. 66, n. 1, p. 72-77, 2001.

AYRES, M.; AYRES JUNIRE, M; AYRES, D. L.; SANTOS, A. S. BioEstat 2.0. Aplicações Estatísticas nas Áreas das Ciências Biológicas e Médicas. Belém: Sociedade Civil Mamirauá; Brasília, DF: CNPq, 2000. $272 \mathrm{p}$.

BARDÓCZ, S. Polyamines in food and their consequences for food quality and human health. Trends in Food Science and Techonology, v. 6, p. 3 41-346, out. 1995.

BJELDANES, L. F.; SCHUTZ, D. E.; MORRIS, M. M. Food Cosmetology Toxicology, n. 16, p. 157-159, 1978.

BRANDÃO, A. L. G. Potencial de formação de aminas biogênicas em peixes de piscicultura. 2002. 65 f. Dissertação (Mestrado em Ciência dos Alimentos) - Faculdade de Farmácia, Universidade Federal de Minas Gerais, Belo Horizonte. 1996. no $7^{\circ}$ dia sob $2^{\circ} \mathrm{C}$. Em nosso estudo, estes valores foram obtidos no $11^{\circ} \mathrm{dia}, \mathrm{a} 1^{\circ} \mathrm{C}$.

Silva et al. (1998) mensuraram as bases voláteis nitrogenadas em Thunnus obesus e Katsuwonus pelamis, verificando um aumento significativo a partir do $9^{\circ}$ dia de estocagem a $4^{\circ} \mathrm{C}$.

Nas amostras de musculatura branca inoculada, que representam a maior parte deste pescado, a rejeição do produto em relação ao teor de BVT deu-se no mesmo tempo que a extrapolação do limite de histamina, ou seja, no $3^{\circ}$ dia para as amostras a $1^{\circ} \mathrm{C}$ e em 12 horas para aquelas a $25^{\circ} \mathrm{C}$.

As amostras não inoculadas mantidas a $1^{\circ} \mathrm{C}$ mostraram rejeição por BVT já no 5ํia de estocagem, enquanto os valores de histamina só alcançaram o limite permitido no $11^{\circ}$ dia. Esta diferença pode ser justificada pelo fato da temperatura de refrigeração ser um fator desfavorável para a produção de histamina. Ao contrário, à temperatura de $25^{\circ} \mathrm{C}$, o limite para histamina foi ultrapassado em 12 horas, enquanto os valores de BVT mostraram rejeição somente em 24 horas.

A correlação dos valores de BVT e histamina não foi realizada neste estudo, tendo em vista a utilização do método semiquantitativo para a determinação de histamina.

\section{Conclusões}

Apesar da produção de histamina ter sido, na maioria das vezes, maior na musculatura branca, em condições adequadas de estocagem $\left(1^{\circ} \mathrm{C}\right)$, esta diferença não afeta o grau de aceitabilidade do produto para este parâmetro, uma vez que o nível máximo permitido foi atingido igualmente no 110 dia de estocagem. Esta afirmação também é válida para as amostras mantidas em temperatura ambiente $\left(25^{\circ} \mathrm{C}\right)$, uma vez que o nível máximo permitido de todas as amostras foi atingido 12 horas após o início do experimento.

A temperatura de refrigeração $\left(1^{\circ} \mathrm{C}\right)$ foi um fator preponderante para a manutenção da qualidade do pescado, uma vez que retardou a produção de histamina, confirmando a importância da cadeia de frio na comercialização deste produto.

BRASIL. Ministério da Agricultura. Secretaria Nacional de Defesa Agropecuária.Laboratório Nacional de Referência Animal Métodos Analíticos Oficiais para Controle de Produtos de Origem Animal e seus Ingredientes. Brasília, 1981. 81p. v. 2. Métodos Físico-Químicos. BRASIL. Port. n 185, de 13 maio 1997. Aprova o regulamento técnico de identidade e qualidade de peixe fresco (inteiro e eviscerado). Diário Oficial [da] República Federativa do Brasil, Brasília, DF, 19 de maio de 1997.

EITENMILLER, R. R.;WALLIS, J.W.;ORR, J. H.;PHILLIPS, R. D. Production of histidine descarboxilase and histamine by Proteus morganii. Journal of Food Protection, n. 44, p. 815-820, 1981.

GINGERICH, T. M.; LORCA, T.; FLICK, G. J.;PIERSON, M. D.; McNAIR, H. $M$. Biogenic amine survey and organoleptic changes in fresh, stored, and temperature-abused bluefish (Pomatomus saltatrix). Journal of Food Protection, v. 62, n. 9, p. 1033-1037, 1999.

HALÁSZ, A.; BARÁTH, A., SIMON-SARKADI; HOLZAPFEL, W. Biogenic amines and their production by microorganisms in food. Trends in Food Science \& Technology, v. 5, p. 42-49, fev. 1994.

HUSS, H. H. Assurance of seafood quality. Lyngby:Ministry of Fisheries Technical University, 1993, 169 p. 
ITO, K. Amino acid composition of the muscle extracts of aquatic animals. Bulletin of the Japanese Society of Scientific Fisheries, v. 23, n. 7-8, p. 497-500, 1957.

JUNG, H., P., K.; BJELDANES, L. F. Effects of cadaverine on histamine transport and metabolism in isolated gut sections of the guinea pig. Food Cosm. Toxicol. 17, p. 629-632, 1979.

LAZSLO, H.; BASSO, L. M.; COELHO, C. M. L. Química de alimentos e alterações dos componentes orgânicos. São Paulo: Nobel, 1986. 98 p. cap. 2: Protídeos, p. 32-43.

LEITÃO, M. F. F.;BALDINI, V. L. S; UBOLDI EIROA, M. N; DESTRO, M. T. Bactérias produtoras de histamina em pescado de origem marinha. Coletânea do Instituto de Tecnologia de Alimentos, v. 13, p. 75-82, 1983.

LIMA, A S.; GLÓRIA, M. B. Aminas bioativas em alimentos. Boletim da Sociedade Brasileira de Ciência e Tecnologia de Alimentos, v. 33, n. 1, p. 70-79, jan.-jun. 1999.

LUKTON, A.; OLCOTT, H. S. Content of free imidazole compounds in the muscle tissue of aquatic animals. In: ANNUAL MEETING OF THE INSTITUTE OF FOOD TECHNOLOGISTS, eighteenth. 1958, Chicago, Illinois. p. 611-617.

SAKAGUSHI, M., MURATA, M.; KAWAI, A. Changes in free amino acids and creatine contents in yellowtail (Seriola quinqueradiata) muscle during ice storage. Journal of Food Science, v. 47, p. 1662-1666, 1982.
SCHUTZ, D. E.; CHANG, G. W.; BJELDANES, L. F. Decomposition in foods (chemical indexes). Journal of Official Methods of the Association Official Analytical Chemists International, v. 59, n. 6, p. 1224-1225, 1976.

SHAKILA, R. J.; VASUNDHARA, T. S.; KUMUDAVALLY, K. V. A comparison of the TLC-densitometry and HPLC method for the determination of biogenic amines in fish and fishery products. Food Chemistry, n. 75, p. 255-259, 2001.

SILVA, C. C. G., PONTE, D. J. B.; DAPKEVICIUS, M. L. N. E. Storage temperature effect on histamine formation in big eye tuna and skipjack. Journal of Food Science, v. 63, n. 4, p. 644-646, 1998.

STRATTON, J. E.; HUTKINS, R. W.; TAYLOR, S. L. Biogenic amines in cheese and other fermented foods: a review. Journal of Food Protection, v. 54, n. 6, p. 460-470, jun. 1991.

VARRIK, E.; VIRU, A.; ÖÖPIK, V.; VIRU, M. Exercise-induced catabolic responses in various muscle fibres. Canadian Journal of Sports Sciences, n. 17, v. 2, p. 125-128, 1992.

VECIANA-NOGUES, M. T.; HERNANDEZ-JOVER, T.;MARINE-FONT, A.; VIDAL-CAROU, M. Liquid chromatographic method for determination of biogenic amines in fish and fish products. Journal of Official Methods of the Association Official Analytical Chemists International, v. 78, n. 4, p. 1045-1050, 1995.

WENDAKOON, C. N.; MURATA, M.; SAKAGUCHI, M. Comparison of non-volatile amine formation between the dark and white muscles of mackerel during storage. Nippon Suisan Gakkaishi, v. 56, n. 5, p. 809818,1990 